\title{
Anatomical Variations of Mental Foramen: A Retrospective Cross-Sectional Study
}

\author{
Variaciones Anatómicas del Foramen Mental: Un Estudio Transversal Retrospectivo
}

\author{
Alrahabi, Mothanna ${ }^{1}$ \& Zafar, Muhammad ${ }^{1,2}$
}

\begin{abstract}
ALRAHABI, M. \& ZAFAR, M. Anatomical variations of mental foramen: a retrospective cross-sectional study. Int. J. Morphol., 36(3):1124-1129, 2018.

SUMMARY: Mental foramen is (MF) an important anatomical landmark that has clinical significance during dental treatments such as placing dental implants or endodontic treatment of mandibular premolars. The location and morphology of mental foramen varies among populations. The aim of this study is to determine the range of variations in the anatomical location and shape of mental foramen. This is a retrospective study conducted using panoramic radiographic (OPG) data of patients. A total of 498 panoramic radiographic images showing erupted lower premolars and first molars were included. All OPGs data were sorted in six study groups and analyzed statistically. The majority of cases (57\%) showed the presence of MF in line with the long axis of 2nd premolar. Only $3.2 \%$ of MFs were in line with the long axis of first premolar. The shape of MF was round in majority (40\%) followed by oval shape (35.7 \%). Irregular shape mental foramens were observed in $24.3 \%$ of cases. The p value $<0.05$ was considered as statistically significant. The anatomical location of mental foramen varies between first premolar to first molar. In terms of shape, the mental foramen ranged from round/oval to irregular. Although, the position and shape varied with age of the patient, there is no predictable correlation between the age and position or shape of mental foramen.
\end{abstract}

KEY WORDS: Mental foramen; Anatomy; Mandible; Morphology; Dental Implants.

\section{INTRODUCTION}

Mental foramen (MF) is an imperative anatomical landmark of the mandible that rests inferior to lower premolars (von Arx et al., 2013). The MF permits the passage of the neurovascular bundles containing the mental nerve, artery and vein to the external surface of the mandible (Aminoshariae et al., 2014). The mental nerve is sensory in nature that is a branch of the inferior alveolar nerve, a major branch of the mandibular nerve originating from fifth cranial nerve. The mental nerve innervates the skin of the chin, the lower lip, mucosa of lower lip and the labial gingiva of lower incisors (Moore et al., 2014). There are a wide range of variations in the MF anatomical locations and shapes. For instance, the oval and round shapes of the MF have been reported in $54 \%$ and $46 \%$ of the mandibles respectively (Fabian, 2007). However, the morphology and location of the MF may vary depending on multiple factors such as genetics, racial differences, sex and age.

The confirmation of anatomical location of the MF is critical to preclude potential injuries to mental nerve during procedures such as periapical endodontic surgery (Moiseiwitsch, 1995), drainage procedures or reflection of a full-thickness mucoperiosteal flaps (Moiseiwitsch, 1998). In addition, precautionary measures are essential during the administration of local anesthetic via infiltration in this area (Loudon, 2011), performing a sagittal split ramus osteotomy (Hashiba et al., 2008) and dental implants insertion (Greenstein \& Tarnow, 2006). The nerve damage can cause temporary or permanent paresthesia in the sensory distribution of the mental nerve leading to a negative outcome and bad experience for the patient (Aminoshariae et al.). Therefore, the sound knowledge regarding the anatomical location and shapes of the MF and likely variations in the morphology are of key importance. A number of non-invasive techniques such as radiography (Sadeghi \& Esmi, 2007; Zafar \& Javed, 2013) and cone beam computed tomography (von Arx et al.; Alrahabi \& Zafar, 2015) have been advocated to identify various anatomical landmarks. The radiographic assessment methods (panoramic and periapical 
radiographs) are non-invasive, convenient for patients and have been used to determine the location of the MF in previously (Chkoura \& El Wady, 2013). The aim of the current study is to determine the variations in the anatomical location and shape of mental foramen among the residents of Saudi Arabia. For this purpose, the retrospective radiographic data of patients have been analyzed.

\section{MATERIAL AND METHOD}

This is a retrospective cross sectional study conducted using panoramic radiographic data of Saudi patients seeking dental treatment at College of Dentistry, Taibah University, Madinah Munnawwarrah during the period of January 2014 to December 2017. The research protocol was approved by the research ethics committee at College of Dentistry, Taibah University (Ref: TUCDREC/20160203/Alrahabi). The requirement of patient's consent was exempted by the college research ethics committee on the basis of using retrospective data anonymously without indicating any personal information of patients.

All orthopentograms (OPGs) were captured using a digital machine (Kodak 9000 extra-oral imaging system, Carestream Health, Rochester NY) and fixed parameters [exposure time $(12.5 \mathrm{~s})$, voltage $(73 \mathrm{kV})$, current $(12 \mathrm{~mA})$ ] and carefully evaluated for the suitability for this study. OPGs showing any abnormalities such as incomplete skeletal growth, excessive bone resorption or patients falling out of the age groups (16-75) were excluded. In addition, OPGs showing any missing/un-erupted premolars or skeletal pathology in the lower jaw were excluded. A total of 498 OPGs (240 males and 258 females) showing fully erupted lower premolars and first molars were included. All-inclusive OPGs were sorted in to six study groups based on their ages and sex (Table I).

Anatomical evaluation of mental foramen. Each OPG was analyzed using the CS dental imaging software (Carestream Health, Rochester, New York, USA) by two observers. The MF was evaluated for its position (in relation to premolars), shape and proximity to the lower margin of the mandible (Table II) using the criteria mentioned previously (Kqiku et al., 2013).

Various positions of MF with the reference to the long axis of premolars (position 1-4) have been described. Following position evaluation, MFs were classified in to three categories oval, round and irregular shape. The proximity of lower margin of each MF from lower margin of the mandible was calculated using the precise ruler tool in CS dental imaging software.

Statistical Analysis. All data was analyzed illustratively using the SPSS software (version. 20 Chicago, IL, USA). In order to detect the statistically significance differences among data sets, Chi-square and t-test were applied. The $\mathrm{p}$ value $<0.05$ was considered as statistically significant.

\section{RESULTS}

A total of 534 OPGs were analyzed during the period of this study (January 2013 to March 2016). Out of these, 36 OPGs were excluded for not fulfilling the inclusion criteria. The final sample size for this study included 498 OPGs (240 male and 258 female patients). The included OPGs were distributed in to study groups according to their sex and age (Table I). All OPGs were evaluated for positioning and shape of MF and its proximity from the lower margin of mandible.

The positioning of MF in the mandible. For any age group, the majority of cases $(57 \%)$ showed the presence of MF at position 3 (In line with the long axis of 2nd premolar), followed by position $2(25.5 \%)$ i.e. the mental foramen lying between the long axis of 1st and 2nd premolars (Table III). Position of MF distal to second premolar (position 4) was observed in $14.3 \%$ of cases. Only $3.2 \%$ of MFs were observed at position 1 (In line with the long axis of 1 st premolar). The position 2 was more frequent in females (16-25 years) age group than the same age group in males. Whereas the position 3 was more frequent in females (26-35 years and 46-55 years) age groups compared to the same age groups in males (Table III).

In general, there were no significant differences ( $p$ $\geq 0.05$ ) among male and female patients in terms of position of MF (Table IV). However, there was a significant difference $(\mathrm{p} \leq 0.05)$ in MF position frequency between males and females in the following age groups (16-25, 2635 and 46-55).

The shape of the mental foramen. In terms of shape of $\mathrm{MF}$, the radiographic data from all age groups was sorted in to three types; oval, round and irregular. In majority of cases (40\%), MF had round shape, followed by oval shape mental foramen that were observed in $35.7 \%$ of cases (Table V). Irregular shape mental foramens were observed in $24.3 \%$ of cases. 
Table I. Description of various study groups and their respective proportions.

\begin{tabular}{llll}
\hline Age groups (years) & Male (M) & Female (F) & All \\
\hline Group 1 (16-25) & $(55) 22.9 \%$ & $(48) 18.6 \%$ & $(103) 20.7 \%$ \\
Group 2 (26-35) & $(49) 20.4 \%$ & $(50) 19.4 \%$ & $(99) 19.9 \%$ \\
Group 3 (36-45) & $(49) 20.4 \%$ & $(50) 19.4 \%$ & $(99) 19.9 \%$ \\
Group 4 (46-55) & $(50) 20.8 \%$ & $(50) 19.4 \%$ & $(100) 20.1 \%$ \\
Group 5 (56-65) & $(30) 12.5 \%$ & $(50) 19.4 \%$ & $(80) 16.1 \%$ \\
Group 6 (66-75) & $(7) 2.9 \%$ & $(17) 3.9 \%$ & $(17) 3.4 \%$ \\
\hline Total & $(240) 100 \%$ & $(258) 100 \%$ & $(498) 100 \%$ \\
\hline
\end{tabular}

Table II. Parameters and variables used for the morphological evaluation of MF.

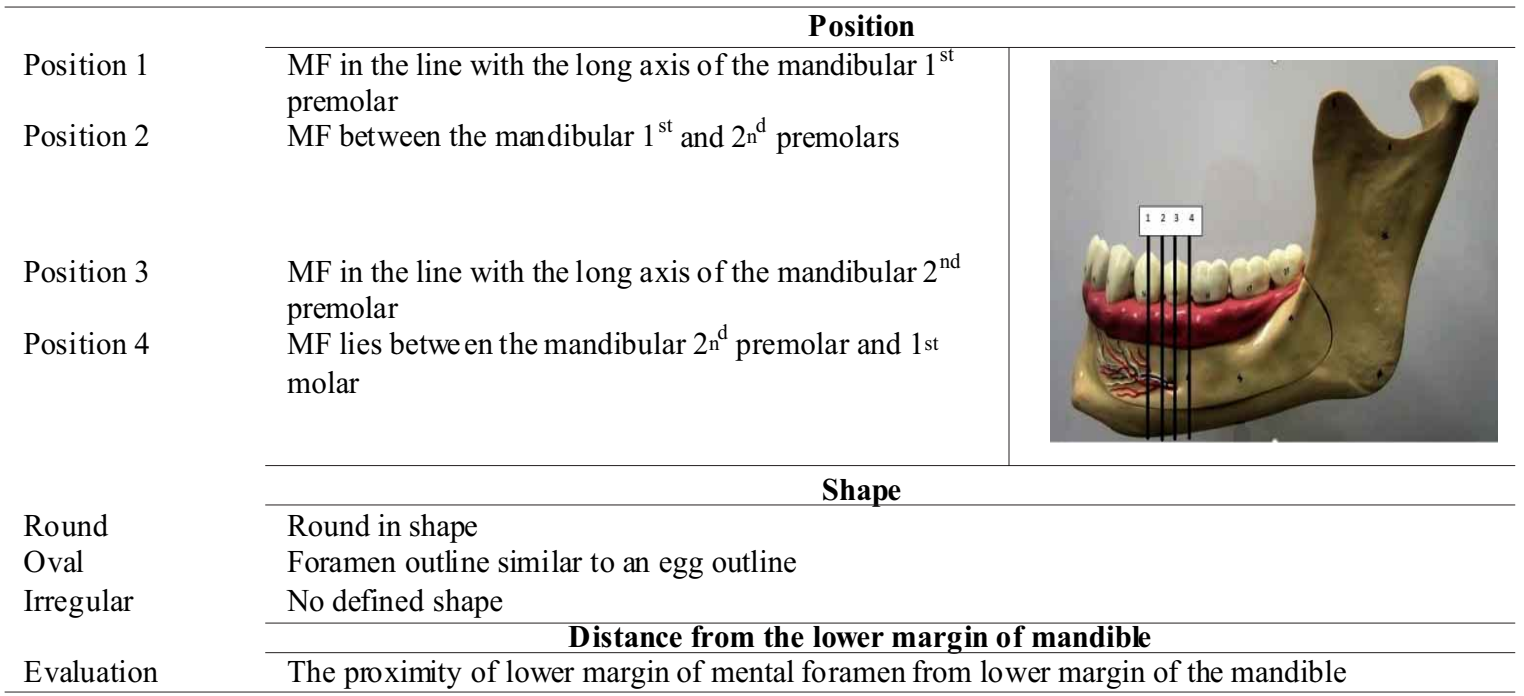

Table III. Distribution (\%) of MF positions according to sex and age groups.

\begin{tabular}{|c|c|c|c|c|c|c|c|c|c|c|c|}
\hline \multicolumn{3}{|c|}{ Position 1} & \multicolumn{3}{|c|}{ Position 2} & \multicolumn{3}{|c|}{ Position 3} & \multicolumn{3}{|c|}{ Position 4} \\
\hline M & $\mathrm{F}$ & All & $\mathrm{M}$ & $\mathrm{F}$ & A1l & $\mathrm{M}$ & $\mathrm{F}$ & All & $\mathrm{M}$ & $\mathrm{F}$ & All \\
\hline 1.8 & 4.2 & 2.9 & 32.7 & 50.0 & 40.8 & 54.5 & 45.8 & 50.5 & 10.9 & 0 & 5.8 \\
\hline 8.2 & 0 & 4.0 & 32.7 & 22.0 & 27.3 & 44.9 & 70.0 & 57.6 & 14.3 & 8.0 & 11.1 \\
\hline 4.1 & 2.0 & 3.0 & 18.4 & 24.0 & 21.2 & 61.2 & 58.0 & 59.6 & 16.3 & 16.0 & 16.2 \\
\hline 2.0 & 6.0 & 4.0 & 24.0 & 16.0 & 20.0 & 44.0 & 72.0 & 58.0 & 30.0 & 6.0 & 18.0 \\
\hline 0 & 2.0 & 1.3 & 30.0 & 16.0 & 21.3 & 63.3 & 60.0 & 61.3 & 6.7 & 22.0 & 16.3 \\
\hline 14.3 & 0 & 5.9 & 0 & 0 & 0 & 71.4 & 40.0 & 52.9 & 14.3 & 60.0 & 41.2 \\
\hline 3.8 & 2.7 & 3.2 & 26.7 & 24.4 & 25.5 & 53.3 & 60.5 & 57.0 & 16.3 & 12.4 & 14.3 \\
\hline
\end{tabular}

Table IV. The statistical analysis of MF positions and shapes according to sex and age groups.

\begin{tabular}{|c|c|c|c|c|c|c|c|}
\hline Age (years) & $16-25$ & $26-35$ & $36-45$ & $46-55$ & $56-65$ & $66-75$ & Total \\
\hline $\mathrm{n}$ & 103 & 99 & 99 & 100 & 80 & 17 & 498 \\
\hline \multicolumn{8}{|c|}{ Position } \\
\hline Chi Square & 7.982 & 8.700 & 0.769 & 13.179 & 5.076 & 4.287 & 3.062 \\
\hline P-Value & $0.046^{*}$ & $0.034^{*}$ & 0.857 & $0.004 * *$ & 0.166 & 0.117 & 0.382 \\
\hline \multicolumn{8}{|c|}{ Shape } \\
\hline Chi Square & 2.751 & 3.217 & 9.855 & 4.706 & 8.206 & 1.036 & 15.194 \\
\hline P-Value & 0.253 & 0.200 & $0.007 * *$ & 0.095 & $0.017 *$ & 0.596 & $0.001 * *$ \\
\hline
\end{tabular}

*Significant at $(\mathrm{p}<0.05) ; *$ Significant at $(\mathrm{p}<0.01)$. 
The oval shape was comparatively more common among females $(41.5 \%)$ than males $(29.6 \%)$. The round shape MFs were more common in males $(48.8 \%)$ compared to females $(31.8 \%)$. Although nor significantly, the irregular shape MFs were slightly more common in females than males (Table V). There were significant differences $(\mathrm{p} \leq 0.05)$ in mental foramen shapes between males and females. In terms of shape of MF, similar trend were observed in the majority of male and female groups and there were no significant differences (Table IV). The distance of lower margin of mandible to MF. The distance of lower margin of mandible to MF varied remarkably among male and female patients regardless of their age groups. Figure 1 compared the mean distance of lower margin of mandible to MF among various age groups. There was no significant difference $(\mathrm{p} \geq 0.05)$ among various age groups with in the same sex (Fig. 1). For male patients, the distance ranged $(0.8-20.2 \mathrm{~mm}$; mean $=11.67$ $\mathrm{mm})$ that was significantly $(\mathrm{p} \leq 0.05)$ higher $(4.4-14.4 \mathrm{~mm}$; mean $=9.54 \mathrm{~mm}$ ) than female patients (Table VI).

Table V. The distribution of various MF shapes according to gender and age groups.

\begin{tabular}{llllllllll}
\hline \multirow{2}{*}{ Age group } & \multicolumn{3}{l}{ Oval shape } & \multicolumn{3}{l}{ Round shape } & \multicolumn{3}{l}{ Irregular Shape } \\
\cline { 2 - 10 } 16-25 years & M & F & All & M & F & All & M & F \\
26-35 years & 16.4 & 35.4 & 35.9 & 47.3 & 35.4 & 40.8 & 16.4 & 29.2 & 22.3 \\
36-45 years & 28.6 & 48.0 & 38.4 & 59.2 & 28.0 & 44.6 & 12.2 & 24.0 & 18.1 \\
46-55 years & 38.0 & 48.0 & 43.0 & 42.0 & 22.0 & 32.0 & 20.0 & 30.0 & 25.0 \\
56-65 years & 23.3 & 52.0 & 41.3 & 30.0 & 28.0 & 29.0 & 40.0 & 20.0 & 30.0 \\
66-75 years & 42.9 & 20.0 & 29.4 & 28.6 & 40.0 & 34.3 & 28.6 & 40.0 & 35.3 \\
\hline Total & 29.6 & 41.5 & 35.7 & 48.8 & 31.8 & 40 & 21.7 & 26.7 & 24.3 \\
\hline
\end{tabular}

Table VI. The statistical analysis of distance between the inferior border of mandible to MF among male and female patients

\begin{tabular}{lllllll}
\hline Studied Variable & Sex & $\mathrm{n}$ & Mean $(\mathrm{mm})$ & Std. Deviation & Std. Error & Range $(\mathrm{mm})$ \\
\hline \multirow{2}{*}{ Distance } & Male & 240 & 11.67 & 2.19 & 0.14 & $0.8-20.2$ \\
Statistical analysis & Female & 258 & 9.54 & 1.78 & 0.11 & $4.4-14.2$ \\
\cline { 2 - 6 } & Mean Difference $=2.14$; Std. Error Difference=0.18 & & \\
p value $=0.000$ (Significant $\mathrm{p}<0.01)$ & &
\end{tabular}

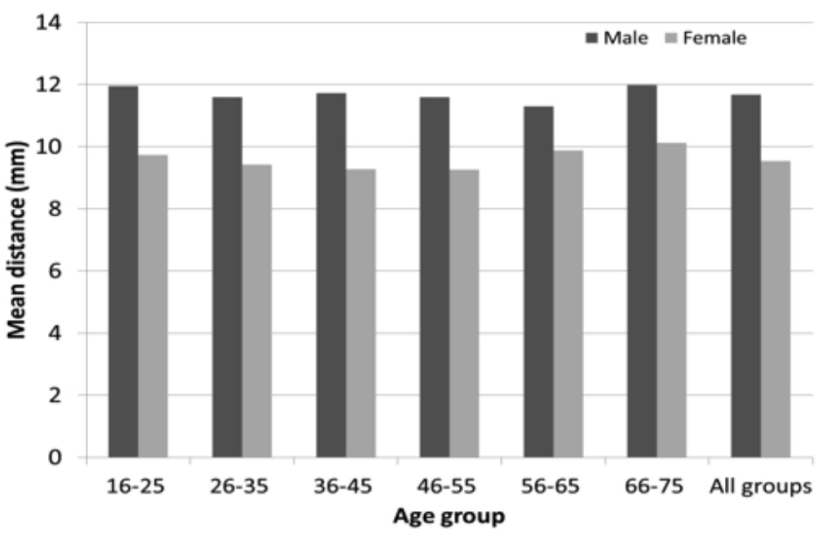

Fig. 1. The comparison of various age groups for mean distance between the inferior border of mandible to MF.

\section{DISCUSSION}

The anatomical location and morphology of the MF is an important parameter while considering the mental nerve anesthetic block and surgical procedures in the labial mental region. In the current study, the variations in anatomical location and shapes of MF in a specified population have been assessed. Significant differences have been reported in the anatomical positioning of MF among various ethnic groups and populations. In the human anatomy textbooks, mental foramen is described to be located typically between the apices of 1st and 2nd premolar (Kqiku et al., 2011). The current study showed that the majority of MF (57\%) remained in the line with long axis of the 2nd mandibular premolar followed by $25.5 \%$ of $\mathrm{MF}$ were in positioned between the long axis of 1 st and 2nd premolars. Only 14.3 $\% \mathrm{MF}$ sat between second premolar and first molar. Comparable results have been reported in a previous study conducted on the Asian Indians; where the majority of mental foramen $(75.3 \%)$ under the apex of 2 nd premolar. In addition, the accessory mental foramens were also observed in $6.2 \%$ of population (Shankland, 1994).

Based on ethnicity and population, a plenty of variations in the anatomical positioning of MF have been described previously. For instance, MF was most common 
located in line with the long axis of $2^{\text {nd }}$ premolar in the Brazilian population (Mendonca Amorim et al., 2008) that is in agreement with this study. In contrast, the longitudinal axis between first and second premolars has been reported to be the most frequent anatomical site for MF among the Chinese (Green, 1987). Santini \& Land (1990) reported similar results among the British residents. Among Europeans, the MF is mostly positioned between the $1^{\text {st }}$ and $2^{\text {nd }}$ premolars (Santini \& Alayan, 2012). In contrast, the current study reported only $25.5 \% \mathrm{MF}$ in this position. The frequent location of MF in the East Asians is reported around the $2^{\text {nd }}$ premolar root apex. Similarly, variations in the MF location have also been reported in Indian and Black African populations (Apinhasmit et al., 2006). In the Turkish population, the most frequent position of MF remained in line with the $2^{\text {nd }}$ premolar long axis (Yesilyurt et al., 2008). The anatomical location of the MF was studied using one hundred dry mandibles belonging to adult blacks of Tanzanian population; the majority of MF (45 $\%)$ were found below the apex of the $2^{\text {nd }}$ premolar followed by $35 \%$ located between the $2^{\text {nd }}$ premolar and 1 st molar and $12 \%$ between the $1^{\text {st }}$ and $2^{\text {nd }}$ premolars. The remaining $8 \%$ were located further distal and below the 1st molar (Fabian). The results of a previous study conducted using dried mandibles are in a close approximation to the results of current study conducted using the retrospective radiographs. It is obvious from the above discussion that there are wide variations in anatomical location of MF. The variability in MF position may be related to different feeding habits subsequently affecting mandibular development and growth (Yesilyurt $e t$ al.). In addition, multiple factors such as muscular biomechanics, teeth morphology, size/shape of face and cranium, habits (dietary patterns, head positions), environmental and socioeconomic factors, along with racial and ethnic miscegenation are likely to affect the anatomical features of jaws (Prado \& Caria, 2007).

In terms of MF shape, the majority of MFs were either round $(40 \%)$ or oval $(35.7 \%)$. However, a significant proportion of MF (24.3\%) had irregular shape. These findings are in agreed with previous results reported by Singh \& Srivastav (2010) in Indian population. Al-Khateeb et al. (2007) reported comparable findings in the Northern Jordanian population. Conversely, there are studies reporting oval shape MFs more frequent compared to round shape. For example, higher frequency of oval-shaped MFs have been reported among Zimbabweans (Mbajiorgu et al., 1998), and Brazilian subpopulations (Oliveira Junior et al., 2009). At present, there are no scientific explanations for such variations in the shape of mental foramen. Perhaps, the anatomical shape of foramen is likely to be controlled genetically and various other factors such as sex, race and bone disorder may contribute to some extent. Although, a few variations in the MF positions among various age groups were observed, there were no statistically significant differences related to age $(\mathrm{p}=0.170)$. Furthermore, no relationship can be established between the MF shape and age or sex. In terms of age group, although we observed significant differences $(\mathrm{p}<0.05)$ in the positioning for certain age groups (16-25, 26-35 and 46-55), no definite correlation was observed between the age and position or shape of MF (Table IV). This in agreement with the previous literature that age is an unlikely factor to affect the incidence of MF positioning (Shankland).

In contrast, the distance between MF and lower margin of mandible was significantly affected by $\operatorname{sex}(\mathrm{p}<0.01)$ and progression of age $(\mathrm{p}<0.05)$. Male patients tended to have significantly greater values compared to the female patients (Table VI). This can be attributed to the factual differences in the dimensions of males and female skeleton (Seeman, 2002). In addition, age changes such as loss of teeth, alveolar bone resorption and remodeling is likely to influence the position of MF. Due to age related hormonal changes among females, the bone physiology (such as resorption, remodeling) changes rapidly (Seeman). These factors are likely to enhance bone resorption and approximation of MF and lower margin of the mandible.

Although the study sample was evenly distributed across the various age groups, the results regarding age as a potentially influencing factor on location, dimensions, and distances of the MF have to be interpreted as trends and need to be substantiated by studies with larger sample sizes. Although the results of this study are based on careful interpretation of OPGs that are two dimensional and panoramic views of three dimensional human tissues; factors such as overlap of tissues, change of angles and patient's movements during radiography might hide some information regarding the anatomical structures.

\section{CONCLUSIONS}

Although the mental foramen is conventionally labelled to be located at the premolar region, the anatomical location of mental foramen varied between first premolar to first molar. The variations in mental foramen shape range from round to oval and irregular. Although, the position and shape varied with age of the patient, there is no predictable correlation between the age and position or shape of mental foramen. The distance of mental foramen and lower margin of the mandible is greater in males compared to females. Considering the anatomical and physiological significance, the operator must keep in mind about the possible variations in the location and morphology of mental foramen prior to undertake local anesthesia or any surgical procedures. In case of any doubt, 
further ingestions such as radiographic evaluation must be sought to prevent nerve severing or any other potential complications.

ALRAHABI, M. \& ZAFAR, M. Variaciones anatómicas del foramen mental: un estudio transversal retrospectivo. Int. J. Morphol., 36(3):1124$1129,2018$.

RESUMEN: El foramen mental (FM) es un hito anatómico importante que tiene importancia clínica durante los tratamientos dentales, como en la colocación de implantes o en el tratamiento endodóntico de los premolares mandibulares. La ubicación y morfología del foramen mental varía entre las poblaciones. El objetivo de este trabajo fue determinar el rango de variaciones en la ubicación y la forma del foramen mental. Este es un estudio retrospectivo utilizando datos radiográficos panorámicos (DRP) de los pacientes. Se incluyeron un total de 498 imágenes radiográficas panorámicas que mostraban premolares inferiores y primeros molares erupcionados. Todos los datos de DRP se clasificaron en seis grupos de estudio y se analizaron estadísticamente. La mayoría de los casos $(57 \%)$ mostraron la presencia de FM en línea con el eje largo del segundo premolar. Solo el 3,2 \% de los MF se alinearon con el eje largo del primer premolar. La forma de FM fue redonda en su mayoría (40\%) seguida de forma ovalada $(35,7$ $\%)$. Se observaron foramen mentales de forma irregular en el $24,3 \%$ de los casos. El valor p $<0.05$ se consideró estadísticamente significativo. La ubicación del foramen mental varía entre el primer premolar al primer molar. En términos de forma, el foramen mental varió de redondo / oval a irregular. Aunque la posición y la forma variaron con la edad del paciente, no existe una correlación predecible entre la edad y la posición o la forma del foramen mental.

PALABRAS CLAVE: Foramen mental; Anatomía; Mandíbula; Morfología; Implantes dentales.

\section{REFERENCES}

Al-Khateeb, T.; Al-Hadi Hamasha, A. \& Ababneh, K. T. Position of the mental foramen in a northern regional Jordanian population. Surg. Radiol. Anat., 29(3):231-7, 2007.

Alrahabi, M. \& Zafar, M. S. Evaluation of root canal morphology of maxillary molars using cone beam computed tomography. Pak. J. Med. Sci., 31(2):42630, 2015.

Aminoshariae, A.; Su, A. \& Kulild, J. C. Determination of the location of the mental foramen: a critical review. J. Endod., 40(4):471-5, 2014.

Apinhasmit, W.; Methathrathip, D.; Chompoopong, S. \& Sangvichien, S. Mental foramen in Thais: an anatomical variation related to gender and side. Surg. Radiol. Anat., 28(5):529-33, 2006.

Chkoura, A. \& El Wady, W. Position of the mental foramen in a Moroccan population: A radiographic study. Imaging Sci. Dent., 43(2):71-5, 2013.

Fabian, F. M. Position, shape and direction of opening of the mental foramen in dry mandibles of Tanzanian adult black males. Ital. J. Anat. Embryol., 112(3):169-77, 2007.

Green, R. M. The position of the mental foramen: a comparison between the southern (Hong Kong) Chinese and other ethnic and racial groups. Oral Surg. Oral Med. Oral Pathol., 63(3):287-90, 1987.

Greenstein, G. \& Tarnow, D. The mental foramen and nerve: clinical and anatomical factors related to dental implant placement: a literature review. J. Periodontol., 77(12):1933-43, 2006.

Hashiba, Y.; Ueki, K.; Marukawa, K.; Nakagawa, K.; Yamamoto, E. \& Matsubara, K. Relationship between recovery period of lower lip hypoesthesia and sagittal split area or plate screw position after sagittal split ramus osteotomy. Oral
Surg. Oral Med. Oral Pathol. Oral Radiol. Endod., 105(1):11-5, 2008

Kqiku, L.; Sivic, E.; Weiglein, A. \& Städtler, P. Position of the mental foramen: an anatomical study. Wien. Med. Wochenschr, 161(9-10):272-3, 2011.

Kqiku, L.; Weiglein, A.; Kamberi, B.; Hoxha, V.; Meqa, K. \& Städtler, P. Position of the mental foramen in Kosovarian population. Coll. Antropol., 37(2):5459, 2013.

Loudon, J. Beware the mental foramen. Br. Dent. J., 210(7):293, 2011.

Mbajiorgu, E. F.; Mawera, G.; Asala, S. A. \& Zivanovic, S. Position of the mental foramen in adult black Zimbabwean mandibles: a clinical anatomical study. Cent. Afr. J. Med., 44(2):24-30, 1998.

Mendonca Amorim, M.; Bevilacqua Prado, F.; Bicalho Borini, C.; Oliveira Bittar, T.; Volpato, M. C.; Groppo, F. C. \& Ferreira Caria, P. H. F. The mental foramen position in dentate and edentulous Brazilian's mandible. Int J Morphol., 26(4):981-7, 2008.

Moiseiwitsch, J. R. Avoiding the mental foramen during periapical surgery. $J$. Endod., 21(6):340-2, 1995.

Moiseiwitsch, J. R. Position of the mental foramen in a North American, white population. Oral Surg. Oral Med. Oral Pathol. Oral Radiol. Endod., 85(4):45760, 1998.

Moore, K. L.; Dalley, A. F. \& Agur, A. M. R. Clinically Oriented Anatomy. Philadelphia, Wolters Kluwer Health/Lippincott Williams \& Wilkins, 2014.

Oliveira Junior, E. M.; Araújo, A. L. D.; Da Silva, C. M. F.; Sousa-Rodrigues, C. F. \& Lima, F. J. C. Morphological and morphometric study of the mental foramen on the M-CP-18 Jiachenjiang point. Int. J. Morphol., 27(1):231-8, 2009.

Prado, F. B. \& Caria, P. H. F. Morphological comparison between Brazilian's mandibles and populations from four continents. Int. J. Morphol., 25(2):3237, 2007.

Sadeghi, S. H. \& Esmi, F. Clinical comparison between extra oral radiography technique with conventional periapical film and intra oral method on working length estimation in molars teeth in endodontics. J. Guilan Univ. Med. Sci., 16(61):15-21, 2007.

Santini, A. \& Alayan, I. A comparative anthropometric study of the position of the mental foramen in three populations. Br. Dent. J., 212(4):E7, 2012.

Santini, A. \& Land, M. A comparison of the position of the mental foramen in Chinese and British mandibles. Acta Anat. (Basel), 137(3):208-12, 1990.

Seeman, E. Pathogenesis of bone fragility in women and men. Lancet, 359(9320):1841-50, 2002.

Shankland, W. E. 2nd. The position of the mental foramen in Asian Indians. $J$. Oral Implantol., 20(2):118-23, 1994.

Singh, R. \& Srivastav, A. K. Study of position, shape, size and incidence of mental foramenand accessory mental foramen in Indian adult human skulls. Int. $J$. Morphol., 28(4):1141-6, 2010.

von Arx, T.; Friedli, M.; Sendi, P.; Lozanoff, S. \& Bornstein, M. M. Location and dimensions of the mental foramen: a radiographic analysis by using conebeam computed tomography. J. Endod., 39(12):1522-8, 2013

Yes silyurt, H.; Aydinlioglu, A.; Kavakli, A.; Ekinci, N.; Eroglu, C.; Hacialiogullari, M. \& Diyarbakirli, S. Local differences in the position of the mental foramen. Folia Morphol. (Warsz), 67(1):32-5, 2008.

Zafar, M. S. \& Alrahabi, M. Cone beam computed tomography for exploring morphology of mandibular first molar. Br. J. Med. Med. Res., 6(5):514-21, 2015.

Zafar, M. S. \& Javed, E. Extraoral radiography: an alternative to intraoral radiography for endodontic (root canal system) length determination. Eur. Sci. J., 9(15):51-61, 2013.

Corresponding author:

Dr. Muhammad Sohail Zafar, PhD (UK); MSc (UK)

Department of Restorative Dentistry

College of Dentistry

Taibah University

41311, Al Madinah

Al Munawwarah

Received: 16-04-2018

SAUDI ARABIA

Accepted: 11-07-2018

Email: mzafar@taibahu.edu.sa; drsohail_78@hotmail.com 